his views on yellow fever and its treatment, the disagreements with his professional colleagues and other incidents of his career are ably set forth by the author. The book is well illustrated by portraits of Hosack and his near relatives. Arthur MacNalty

\section{THEORY OF PROBABILITY}

Mathematical Theory of Probability and Statistics By Richard von Mises. Edited and Complemented by Hilda Geiringer. Pp. xiv +694. (New York: Academic Press, Inc.; London: Academic Press, Inc. (London), Ltd., 1964.) $157 s$.

MATHEMATICAL Theory of Probability and Statistics is a comprehensive account of the ideas of von Mises edited and complemented by his pupil Hilda Geiringer from much unpublished material. It will be welcomed as an easily available account of von Mises's ideas on the theory of probability.

There are basically two approaches to the theory of probability. The one adopted by many mathematicians, of whom perhaps the best known is Kolmogoroff, is broadly as follows. In probability we are concerned with 'events' to which are attached certain numerical functions which measure the probability of each event. The mathematician writes down statements about these events and their probabilities which appear to him to be their essential physical properties. Having done this he looks for a mathematical model the axioms of which express, in abstract language, these physical properties. In the present case he finds this to hand in Boolean algebra and measure theory. This means that results in probability can be expressed in purely mathematical terms in the language of measure theory. The connexion with the real world is there, but it appears only in the basic assumptions and the agreement between the conclusions of the theory and practice. But the reasoning is mathematical throughout; the events have lost their physical meaning and become elements of some abstract algebra. This would not be so bad if to every element in the algebra we could attach some physical meaning, but this is not true; most of the elements have only a mathematical significance. It is on this ground that some mathematicians, of which von Mises is perhaps the best known, preferred an alternative theory. In their minds an event and the probability of an event have a physical significance which should be preserved throughout the theory. Their approach is usually referred to as a 'frequency' theory in contrast to the measure theoretic approach described here.

The aim of those who adopt the frequency approach is to preserve the physical significance of the concepts throughout and to deal only with events which have a physical significance. However, the theory has to satisfy the requirements of an exact science and this cannot be done without a mathematical interpretation of the physical concepts. The very idea of defining a probability as the limit of the frequencies of observed events is a mathematical one and we are once again forced to construct a mathematical model of that portion of the physical world which occupies our attention. This is what von Mises set out to do. His theory is just as much a mathe. matical one as that of Kolmogoroff. Its main difference is that it sets out to consciously conform to our physical intuitions as closely as possible. In this way it has a stronger appeal to scientists who like to think in physical terms.

The first two chapters in the book under review give the basic ideas of von Mises, the contributions of Wald and the related axioms of Tornier. Though Tornier gives an axiomatic formulation of his ideas, in the opinion of the editor, his theory is a frequency theory. The frequency theory is then compared and contrasted with the measure theory approach.
In Chapters 3-8 most of the familiar results of probability are developed and formulated in the language of frequency theory. Chapters 9-12 deal with the analysis of statistical data inference and correlation. Throughout there is a wealth of examples and practically all results are expressed in concrete terms. Abstract formulation is carefully avoided. Some subjects like conditional probability are dealt with very slightly. The book gives a clear exposition of von Mises's ideas and is therefore a valuable addition to mathematical literature.

A. C. OFFORD

\section{CONCEPTUAL SYSTEMS IN SCIENCE}

Matter and Method

By R. Harré. Pp. $x+124$. (London: Macmillan and Co., Ltd.; New York: St. Martin's Press, Inc., 1964.) 16s. net.

$T$ HE first part of Mr. Harré's new book deals with scientific explanation in terms of what he calls "general conceptual systems", while the second expounds the change from the Aristotelian to the corpuscularian general conceptual system which occurred around the seventeenth and eighteenth centuries. Mr. Harré aims at providing students of philosophy with a better comprehension of the scientific background for the ideas of the British empiricists, and scientists with a better understanding of the nature of conceptual change and how it affects scientific discovery. He starts by distinguishing reticular theories, which merely correlate phenomena, and explanatory theories, which make reference to theoretical entities. This distinction is not made very clear, since he includes Newtonian mechanics in the former, although reference is made to forces, which would seem to be theoretical entities, while the latter include the phlogiston and oxygen theories. We are not told why the "oxygen hypothesis" is a theoretical, as opposed to a phenomenal, explanation; both solids and gases are, surely, phenomenal entities. Incidentally, it is very misleading to say that "from Black and Cavendish Lavoisier had the novel idea of a quantitative study of chemical reactions" [p. 19, my italics], when in fact Jean Rey had discovered 150 years earlier that in the calcination of tin the calx weighs more than the tin from which it is formed.

Theoretical entities, according to Harré, can be linked with what we observe either causally or modally. As an example of the first, "the increase in average momentum of a gas causes the pressure to increase"; as an example of the latter, "average kinetic energy of the molecules of a gas" just is temperature; these are "two different aspects of the same phenomenon" (p. 20). But we are not told of any logically relevant differences between causal and modal linkings, for example, with respect to their presumably logically diverse methods of verification. However this may be, there is a hierarchy of explanatory mechanisms, one group of which is considered, for a given historical period, ultimate or final in that it does not, in that period, call for further explanation. The characteristics of this ultimate mechanism are expressed in what Harré calls the "general conceptual system" of that period. The rest of the first part of the book discusses reasons for accepting and for modifying particular general conceptual systems. This, although sometimes interesting and original, is often confused, partly because it is too brief, and partly because the relationships between empirical observation, $a$ priori reasoning and linguistic innovation are not made clear. The same criticisms hold of the second, more historical, part of the book. Harré points out that he is interpreting, rather than expounding, the ideas of Gassendi, Galileo, Locke, Newton, etc.; but sometimes these interpretations seem perverse or just wrong, while bad syntax makes the book often completely incompre. hensible.
ARDON LYON 